\title{
Undergraduate Research Program to Recycle Composite Waste
}

\author{
Waleed Ahmed ${ }^{1, *} \mathbb{D}$, Essam Zaneldin ${ }^{2} \mathbb{D}$ and Amged Al Hassan ${ }^{3}$ \\ 1 Engineering Requirements Unit, UAE University, Abu Dhabi P.O. Box 15551, United Arab Emirates \\ 2 Department of Civil and Environmental Engineering, UAE University, \\ Abu Dhabi P.O. Box 15551, United Arab Emirates; essamz@uaeu.ac.ae \\ 3 Mechanical Engineering Department, UAE University, Abu Dhabi P.O. Box 15551, United Arab Emirates; \\ aelhassan_97@uaeu.ac.ae \\ * Correspondence: w.ahmed@uaeu.ac.ae
}

check for updates

Citation: Ahmed, W.; Zaneldin, E.; Al Hassan, A. Undergraduate Research Program to Recycle Composite Waste. Educ. Sci. 2021, 11, 354. https://doi.org/10.3390/ educsci11070354

Received: 19 April 2021

Accepted: 25 June 2021

Published: 16 July 2021

Publisher's Note: MDPI stays neutral with regard to jurisdictional claims in published maps and institutional affiliations.

Copyright: (C) 2021 by the authors Licensee MDPI, Basel, Switzerland. This article is an open access article distributed under the terms and conditions of the Creative Commons Attribution (CC BY) license (https:/ / creativecommons.org/licenses/by/ $4.0 /)$.

\begin{abstract}
With the rapid growth in the manufacturing industry and increased urbanization, higher amounts of composite material waste are being produced, causing severe threats to the environment. These environmental concerns, coupled with the fact that undergraduate students typically have minimal experience in research, have initiated the need at the UAE University to promote research among undergraduate students, leading to the development of a summer undergraduate research program. In this study, a recycling methodology is presented to test lab-fabricated Carbon-FiberReinforced Polymer (CFRP) for potential applications in industrial composite waste. The work was conducted by two groups of undergraduate students at the UAE University. The methodology involved the chemical dissolution of the composite waste, followed by compression molding and adequate heat treatment for rapid curing of CFRP. Subsequently, the CFRP samples were divided into three groups based on their geometrical distinctions. The mechanical properties (i.e., modulus of elasticity and compressive strength) were determined through material testing, and the results were then compared with steel for prompt reference. The results revealed that the values of mechanical properties range from 2 to $4.3 \mathrm{GPa}$ for the modulus of elasticity and from 203.7 to $301.5 \mathrm{MPa}$ for the compressive strength. These values are considered competitive and optimal, and as such, carbon fiber waste can be used as an alternate material for various structural applications. The inconsistencies in the values are due to discrepancies in the procedure as a result of the lack of specialized equipment for handling CFRP waste material. The study concluded that the properties of CFRP composite prepreg scrap tend to be reusable instead of disposable. Despite the meager experimental discrepancies, test values and mechanical properties indicate that CFRP composite can be successfully used as a material for nonstructural applications.
\end{abstract}

Keywords: composite waste; recycling; material testing; engagement; undergraduate

\section{Introduction}

The dynamics of the planet are rapidly changing with the growing population and increased human activities. Huge metropolitan and industrial estates are springing up, which generate extremely large amounts of waste every single day. Waste management is, therefore, becoming a global issue. One of the prominent wastes of modern-day industry is composite waste [1]. Apart from this, there is a financial impact related to the issue, too, since composites are expensive, and disposing of them not only results in financial losses but also leads to the exhaustion of the available limited resources. In an attempt to investigate this interesting issue, the research sector of the UAE University acknowledged the plight of global waste management issues and has designed an undergrad research program to boost research and development among its undergraduate students. Apart from the global waste management and environmental concerns, the UAE University also recognizes the fact that composites are the 'building blocks' of the future because of their broad range of desirable engineering benefits such as stiffness and strength properties, 
weight reduction, and tendency to withstand rigid dimensional stability. Other benefits include active process cycles and comparatively good resistance to fatigue and failure (concerning metals and ceramics, etc.) [2]. The UAE University is a leading research institution in the Middle East planning to boost the culture and popularity of research and development among its undergraduate students. This initiative to encourage research among undergraduates came in response to the increased undergraduate research efforts by many universities in recent years [3,4]. This research vision of the UAE University is in line with the country's vision to address the most critical and current challenges in today's world through faculty members' and students' research activities. These focused research activities at the UAE University significantly contribute to the development of the country in several strategic areas related to the oil, health, and sustainable energy industries. In the summer of 2017, the UAE University started a new and essential initiative called the 'Summer Undergraduate Research Experience (SURE)' program. The SURE program was established to promote the engagement and contribution of undergraduate students in research activities. This initiative helped train undergraduate students, granted them exposure to research work, and encouraged them to get engaged in several research opportunities while collaborating with other students from different disciplines at the undergraduate and graduate levels under the supervision of experienced faculty members. This initiative provided great opportunities and support for undergraduate students by getting them involved in research activities and preparing them to be promising researchers in the future. According to the UAE University research affairs sector, the number of students that participated in the summer undergraduate program in its first cycle in 2017 was 108 students, working on 27 research projects. This number has witnessed an increase of $40 \%$ in the confirmed projects of the following year. The novelty of this study is that it focuses on research conducted by undergraduate students as part of their education. Undergraduate students typically earn their bachelor's degree with very limited, if any, experience on how to conduct research.

The authors of this research acknowledge the financial support of the research sector at the UAE University for undergraduate research programs sponsored through local companies in the country. In this study, a project for recycling and analyzing the reuse potential of composite waste materials was awarded to university students. Undergraduate students at the UAE University worked on a summer research project to analyze a recycling methodology and test lab-fabricated Carbon-Fiber-Reinforced Polymer (CFRP) for potential applications in industrial composite waste. The following subsections present previous research efforts related to undergraduate research programs, an overview of waste treatment, and a description of carbon-fiber-reinforced polymer.

\subsection{Previous Research Efforts by Undergraduate Research Programs}

Taraban and Blanton [5] and Lopatto [6] summarized numerous vital conclusions that have arisen from studied cases, reviews, and qualitative studies to determine the best practices for managing undergraduate research programs and to figure out whether participating in undergraduate research is advantageous for students. Many gained skills have been focused on and investigated by many universities [6], such as self-confidence, scientific understanding, and obligations to research and science. As such, the hypothesis that undergraduate research programs stimulate students to gain skills and self-confidence, as well as helping them in their careers and education, has been maintained. Bridger and Ford [7] presented an open-laboratory approach to bridge the gap between academia and manufacturing. The proposed method helps in building long-range grants and innovative work associations between academia and industry. In another study, Chris et al. [8] investigated the relationship between undergraduate research participation and learning goals and outcomes. The authors also examined the relationships in the research opportunities for students in different disciplines and study areas evaluated over 4 years. This research effort also presented the benefits and learning goals identified by the undergraduate research students considered in the study. The results of the study indicated that undergraduate 
research is a practical and powerful experience and provides attractive benefits to undergraduate students, regardless of their discipline or area of study. It is worth mentioning that the experienced benefits can be different for undergraduate students depending on their discipline. [9].

The result of a survey conducted among several undergraduate research programs revealed helpful information about the design and execution of undergraduate research opportunities as well as the gained benefits. The survey results also concluded that the involvement of undergraduate students in research activities to gain research experience that would affect the students' success needs more comprehensive studies to consider more factors in these studies. Marcus et al. [10], for example, studied the impact of the participation of undergraduate students from different disciplines on their credit hours and GPA. The value and advantages of undergraduate research programs have been measured through the growth in the interested students and staff members in previous years. However, despite a rise in the number of students participating in undergraduate research programs, there is a lack of published studies to evaluate faculty observations of taking part in undergraduate research activities and the impact on students who took part in such programs. It has been reported by Karen et al. [11] that institutional and individual characteristics can predict students' and faculty members' involvement and the significance of this involvement. In education research, the efficiency of professional-oriented education is dependent upon the inspiration of undergraduate students and their aim of using their research abilities after graduation. Griffioen [12] investigated the relationship between undergraduate students' goals and how students use their research capabilities for a future professional career. The study also examined students' experiences and views regarding research and research activities. The study concluded, from students' viewpoint, that using undergraduate research in future professional work has nothing to do with research activities and has a negligible effect on their views toward research.

It was reported in the literature that students' research attitude should be taken into consideration to boost the functionality of the research integration into educational pedagogies. The motivation of faculty members to supervise undergraduate students was examined and evaluated using empirical data induced by recognizing parameters that permit and restrain faculty involvement in the undergraduate research program. A conceptual model was developed for this purpose to assess the costs-to-benefits ratio, situational and dispositional factors, former expertise, and the demographic considerations and staff incentive for supervising students [13]. It was found that those who liked to be mentors in undergraduate research programs placed a higher emphasis on the opportunity to enhance the educational diversity during advisership. The study also concluded that academics believe that mentoring undergraduate students is time-consuming. The study revealed that, in addition to accessibility constraints, institutions do not grant enough rewards for mentoring undergraduate students. The influence of the undergraduate research, as a form of the students' learning engagement, was discussed by Wolf [14]. In this study, the participated students in the undergraduate research program were asked to do assessment essays that were used in the study. Moreover, the program's attempts to increase students' chances of participating in undergraduate research programs were examined in light of the obstacles that research universities face. Students were introduced to flow visualization experiment research in fluid mechanics during their first Fluid Mechanics course. Stefanucci [15] indicated that performing research with undergraduate students for publishing is very rewarding and faculty members should devote time to this purpose. The author, therefore, suggested exploring means to allocate time for performing research and publishing papers with undergraduate students while delegating mentoring tasks to others. Copper et al. [16] identified the pros and cons of having research labs for providing undergraduate students with research opportunities and experience. The study also revealed that the demographic information of students (e.g., race, gender, ethnicity, college, and graduate point average) affects student' decisions to continue doing research or not. Adams [17] indicated that mentors pave the way for committed undergraduate 
students who contribute to the process of delivering publishable-quality work if students are inspired to meet the targets set by their superiors. Long et al. [18] described a strategy for establishing undergraduate research focused on a Bachelor of Science in a nursing program working in small groups with a faculty mentor. Mann et al. [19] explained that the investigative and experiential aspects of undergraduate research activities, as well as the scientific communication exercises, are beneficial for improving soft skills such as problem solving, strategic reasoning, and communication. Peifer [20] adopted some strategies that assist students in creating outstanding research opportunities that can be published. The study also identified the role of faculty members in mentoring such research activities. Liu et al. [21] suggested guidance to assist undergraduate students in locating research topic opportunities and communicating with groups in a research environment, and the recommended system proved to facilitate this goal. Another community of the University of Alabama in Huntsville students had many academic chances to obtain hands-on experience designing composites and fabricating various structural components [22]. During the program's last year, undergraduate mechanical engineering students participated in an undergraduate research program that resulted in publications in foreign research journals [23]. An investigation was carried out to explore the action learning approach and its possible use in undergraduate engineering education research activities. A case study was presented where a learning environment was established and found to help enhance students' learning and performance [24]. In a Numerical Analysis of Engineering Systems course, an approach was adopted for introducing undergraduate research to engineering students, which is mainly in the early enrolment level for the undergraduate curriculum, that exists in most engineering departments [25]. Finally, a review of how a patent on a rotary diesel engine, which collapsed in operation, was used to link undergraduate research and teaching practices [26].

\subsection{Brief Overview on Waste Treatment}

Waste treatment refers to the activities required to ensure that waste has the most negligible impact on the environment. Some examples of waste forms include agricultural wastewater, biomedical waste, chemical waste, construction waste, demolition waste, electronic waste, food waste, green waste, hazardous waste, industrial waste, mining waste, municipal solid waste, radioactive waste, scrap metal, sewage, toxic waste, and wastewater. Waste treatment is essential for controlling environmental pollutants, even those with the least impact on the environment. In essence, there are various forms of waste treatment in different country and several waste treatment methods. Among these methods are the thermal treatment (incineration, gasification and pyrolysis, and open burning), biological treatment (composting and anaerobic digestion), and dumps and landfills (sanitary landfills, controlled dumps, and bioreactor landfills). One of the prominent wastes today is waste resulting from composites. This study focuses on waste resulting from CFRP.

\subsection{Carbon-Fiber-Reinforced Polymer}

One of the industry's most abundantly used composites is Carbon-Fiber-Reinforced Polymer (CFRP). The strength-to-weight ratios of CFRP composites are high, which explains why they have widescale applications in the aerospace, military, transport, and logistics sectors. In order to reach sustainability for powerful waste management, there is a need for education to contribute positively to assistance in reducing people's waste through promoting environmentally friendly practices beyond the typical image about waste disposal [27]. Many initiatives adopted different ways to encourage environmental sustainability through the universities, even by developing e-learning activities that could facilitate the integration of sustainability concepts and practices in engineering and chemical education by using an online learning forum, where the students participated in an online discussion on the role of engineering to achieve environmental sustainability 
goals [28]. Currently, CFRP waste is mostly disposed of at landfill sites, junkyards, airports, ship docks, etc. [29]. Prompt management of composite waste is crucial as:

(i) Manufacturing composites from nonrenewable resources burden resources and waste management raise environmental concerns as they contribute to land and water pollution.

(ii) Legal constraints on manufactures for disposing of the EoL waste on their own. Automobiles discarded after 2015 are required to be 85 percent recyclable, for example, limiting legitimate CFRP landfilling. The European Union has enacted tight regulations in this region. [30].

(iii) Composites have insufficient economic feasibility, manufacturing electricity consumption (up to $165 \mathrm{kWh} / \mathrm{kg}$ ) and the cost of the materials (up to $£ 40$ a kilogram) [26]. This calls for prompt measures for the re-entry of the materials into the market, thereby converting expensive waste disposal into cost-effective recycling of reusable materials and creating overall better sustainability.

(iv) Most landfill sites are getting filled up, and dumping waste is getting expensive; the cost of legally ejecting CFRP from a landfill may be as low as $0.20 £ / \mathrm{kg}$ [31].

There are two major approaches for the successful management, handling, and recycling of industrial composite waste. The approaches are discussed as follows:

(i) Mechanical recycling: composites are decomposed by employing crushing, shredding, milling, or similar mechanical processes. The composite shreds are segregated viz. powder (resin-enriched) and fibers (fiber-enriched), which are then used as reinforcements in the construction industry for optimizing integrity and strength of the structures (i.e., asphalt fillers, cement minerals, etc.) [32].

(ii) Fiber Reclamation

This recycling technique involves the shredding or powdering of the composites by employing thermal or chemical processes (it breaks down the matrix) [33]. Subsequently, these fibers are further reimpregnated with new resins (i.e., epoxy) to manufacture CFRPs. This reclamation procedure is further classified by pyrolysis (thermal breakdown at $450-700{ }^{\circ} \mathrm{C}$ in an inert atmosphere); fluidized-bed oxidation (thermal breakdown through combustion in the oxygen-rich atmosphere) [34]; and chemical recycling (CFs are inert and are extracted later after chemical degradation in reactive solvents to acquire oligomers.) [3]. In this research, two groups of undergraduate students worked on recycling carbon fiber waste produced by local companies. The two groups worked for one year to study the leftover CFRP waste properties and develop practical solutions for handling the waste rather than dumping it in a landfill. Some of the outcomes of the students' experience is publishing the current work as well as issued patents. The work elaborates on the advantages and disadvantages of undergraduate research programs, identifying and highlighting the programs' positive points. This study also highlights the importance of having undergraduate students involved in research activities as part of the higher educational process.

\section{Methodology}

\subsection{Safety Is a Priority}

For new students involved for the first time in research, conducting a lab orientation is an essential step of learning since it offers the students the required and essential information about the lab and hazardous material [35], especially when dealing with prepreg waste. The conducted lab orientation involved a hands-on practice where students attended a lab session led by a safety engineer taking the students for a lab tour to educate them about health and safety issues and rules, demonstrating essential information about lab equipment that would be used in research as well as addressing health concerns and potential risks when handling the prepreg waste pertaining to the material specifications. 


\subsection{Material Handling}

The expanded usage of carbon-fiber and glass-fiber-reinforced polymer in the market and landfill disposal constraints have necessitated the developing of effective compositematerial-recycling technical solutions. Chemical, mechanical, and thermal methods have been adopted widely for recycling composite material $[36,37]$. There are many possible recycling methods, such as thermal energy recovery by incineration, pyrolysis, and landfilling disposal. The main difference between incineration and pyrolysis is that incineration is the combustion of organic matter in the presence of oxygen. By contrast, pyrolysis is the combustion of organic matter in the absence of oxygen. Although the recycling method is the most viable of all the processes, a major concern is associated with it: The recycled waste material is chemically and mechanically deteriorated; therefore, it is crucial to preassess the different properties of the materials, which may be vital for the production of nonstructural elements for various applications, i.e., CFRP.

These assessments are vital for the following: promoting a clear understanding of the material properties, relevancy to application, and constraints that are attached with the recycling process; appreciating the benefits of the process to reduce the negative impact of the waste dumped in the landfill; saving energy due to minimizing the producing new material that can be linked to the type of the waste; and the target application that would be considered to use the recycled materials, where the mechanical properties are considered to be some of the important parameters that leverage the choice of the end product [29].

\subsection{Constraints}

One of the main challenges of using virgin instead of recycled material is the associated energy and the high cost of recovering the substantial value from CFRP. As a consequence, students were involved in handling the environmental assessment of the recycling process as well as the financial feasibility for different waste material recycling management processes. Efforts have been undergoing to assess the material life cycle and the environmental prediction models to quantify the environmental and financial effects of the waste treatment to compare assorted recycling methods adopted commercially such as microwave, pyrolysis grinding. These techniques could be adopted commercially to replace different materials such as carbon fibers by using the recycling process of the carbon prepreg wastes that would reduce the production cost and become an attractive solution compared to incineration and landfills, which cost very much due to the strict regulations imposed. The capacity of the recycling and the fibers' recovery rate are crucial for reducing the cost of recycled carbon fiber and Global Warming Potential consequences [38].

\subsection{Method}

The work presented in this study demonstrates the recycling process of the prepreg carbon fiber. The experimentation procedure is comprised of several steps. The first step is the resin formulation, composed of manual mixing of different amounts of epoxy monomers and curing agents in aluminum cans to ensure a constant homogeneity. Subsequently, the samples were thermally analyzed and heated to proceed for curing. Modulated Differential Scanning Calorimetry (MDSC) tests are then carried out to determine the Glass Transition Temperature $(\mathrm{Tg})$ of the pieces. The expected effect of heat resulting from such composites is explained by Turhan et al. [39].

Yijia et al. [40] employed the samples' chemical dissolution at the temperature ramp of $1.5^{\circ} \mathrm{C} / \mathrm{min}$ to $250^{\circ} \mathrm{C}$, for about $30 \mathrm{~min}$. An adequate thermal analysis showed that this cure cycle is appropriate for adequate curing of the samples. The oven-cured samples were retested in MDSC and then processed in chemical dissolution containers. However, there are two approaches via oxidative digestion and alkali digestion. A resin concentration of $10 \mathrm{mg} / \mathrm{mL}$ was tested under both methods, whereas dissolution time was measured by visual observation of the procedure (i.e., the time required for the resin to dissolve). Experimental techniques depict the oxidative approach as being more viable for the purpose. 


\subsection{Material Testing}

The composite material was soaked in a chemical solution (i.e., ethylene glycol) by increasing the temperature; therefore, a dissolving process of the epoxy matrix occurs. The ethylene glycol molecules participating in the reactions of the bond exchange within the covalent adaptable network. This successfully leads to breaking the chains of the long polymer into small portions.

The processed prepreg carbon can be recovered with close mechanical properties similar to the virgin ones. The dissolution process rate and the minimum quantity of ethylene glycol necessary to dissolve the covalent adaptable network completely that was concluded experimentally. The dissolved solution causes repolymerization of the epoxy matrix due to further heating; therefore, a different group of composites was made by employing reprocessed prepreg. Accordingly, fully recycled material could be achieved. On the other hand, composites made with epoxies that contain defects at the surface are presented to be entirely repaired. The repaired composites and the recycled demonstrate a similar quality of mechanical properties compared to the virgin materials [41]. Eventually, several domestic legislation and policies that are compliant with the international regulations were adopted to manage waste disposal and recycling in UAE, including the Environment Agency of Abu Dhabi, to improve and control the waste management domestically within the UAE. In general, waste producers and recycling companies, storage waste, and waste disposal are responsible for complying with the competent authority for waste management. Therefore, integrated efforts by all relevant parties are necessary to harmonize the massive efforts to minimize the waste generated by different industries. It becomes a responsibility to reduce the generated waste and to adopt different recycling techniques to rescue the waste material by safely managing the waste to provide innovative and practical solutions to handle the different types of material waste effectively and to focus on the main concern and the best procedures for waste disposal [42]. Accordingly, this research was conducted under the sponsorship of a domestic waste producer in the country and the internal funding of the UAE University research sector as a commitment toward the community and the environment to reduce the harmful impact of CFRP waste produced by local companies.

\section{Experimentation}

In this paper, two groups of students participated in recycling waste CFRP produced by a domestic manufacturer of aircraft parts. The two groups managed to attract the sponsorship of a local industrial company (Mubadala) to sponsor the research proposal financially. The duration of the project was one year and was carried out through the undergraduate research fund for aerospace that was established in the mechanical engineering department of the college of engineering at UAE University. The team managed to obtain funding from a domestic company, Mubadala, based on a proposal to recycle the produced waste from its subsidiary company (STRATA) that generates CFRP waste. The plan was to collect CFRP waste and shred it by a shredding machine into small pieces and to process the waste using two different methods, using a similar curing process for curing virgin CFRP, which is mainly used for producing aircraft structures. A tensile test was then performed on the cured pieces to investigate the mechanical properties of the recycled CFRP. A team of five female students in their fourth year at the mechanical engineering department studied the principles and applications of the composite material. The five students were carefully selected for this task as they had high GPAs and successfully completed the "Engineering Materials" course. The selected students are highly committed, with excellent technical skills gained from taking various classes from other departments in the college. As part of the submitted proposal, a complete plan was prepared and submitted to the steering committee of the research program with a month-by-month detailed outline and the anticipated takes and deliverables. Two supervisors monitored the progress of the team. The experimental procedure plan was divided among the two groups of students for fair participation in the task. According to the research plan, the group was 
requested to attend a full-day training session at the sponsor's facility using the composite material's autoclave process. A professionally experienced employee trained the students to prepare the composite material from scratch for the autoclave process. The training was valuable for students since this was the first time to experience such a high level of training under the company's strict conditions for training their employees. Students were also introduced to all materials, tools, procedures, and safety requirements for composite material used for handling aircraft components. At this stage, the shredded CFRP prepared before conducting the training was cured using the traditional autoclave process used by STRATA manufacturing company for aircraft parts. The shredded CFRP preparation for the autoclave process is illustrated in Figure 1.
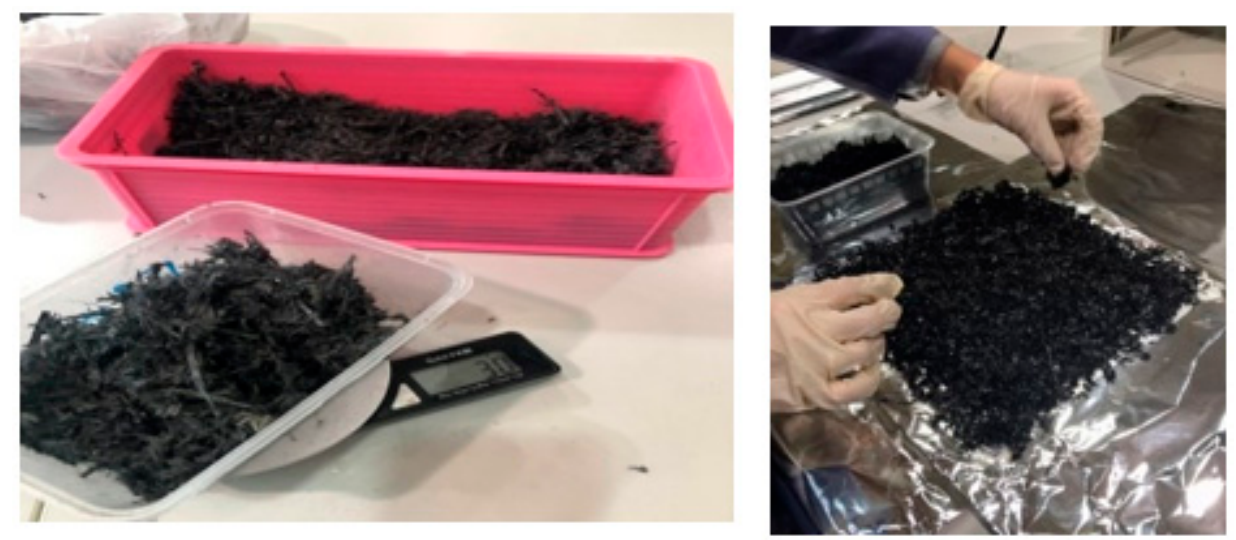

Figure 1. Shredded CFRP preparation for the autoclave process.

Two aluminum plates ( $3 \mathrm{~mm}$ thick) were used to compress the shredded CFRP. The shreds were foiled by aluminum foils that were cast using molds to release wax of hightemperature resistance. A sandwich of the two aluminum plates was then constructed by placing the foiled shred in between them. The sandwich was subjected to a preparation stage in order to prepare the autoclave vacuum process to perform the curing cycle. Students were carefully trained and supervised to carry out the preparation stages and the testing as per the actual process. At the end of the training, the waste CFRP was ready to be cured by the autoclave. Students were eventually introduced to the autoclave and the curing process. The prepared sample was connected to the vacuum hoses and placed inside the autoclave, as shown in Figure 2.

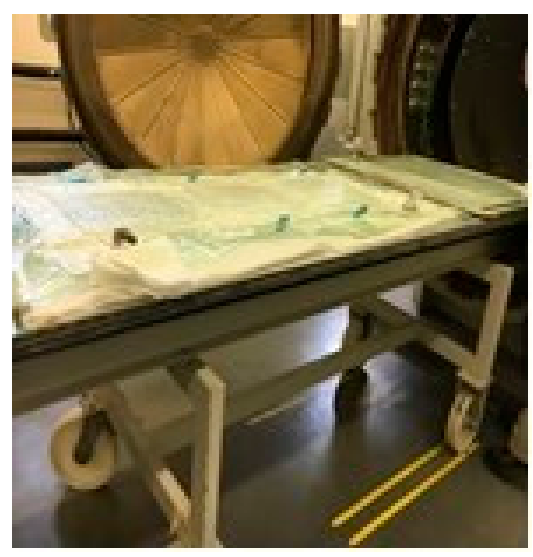

Figure 2. Autoclave to process the waste CFRP under the curing cycle.

The autoclave was set for a vacuum of 3 bar and at a curing temperature of $180{ }^{\circ} \mathrm{C}$ that lasts for three hours, passing through an increasing, steady, and cooling cycle, as customarily used. At this stage, students were asked to write a report to document the whole procedure and to present their experience, observations, and findings of the 
conducted training. After finishing the curing process and waiting until the next day, the cured CFRP was collected, as shown in Figure 3.

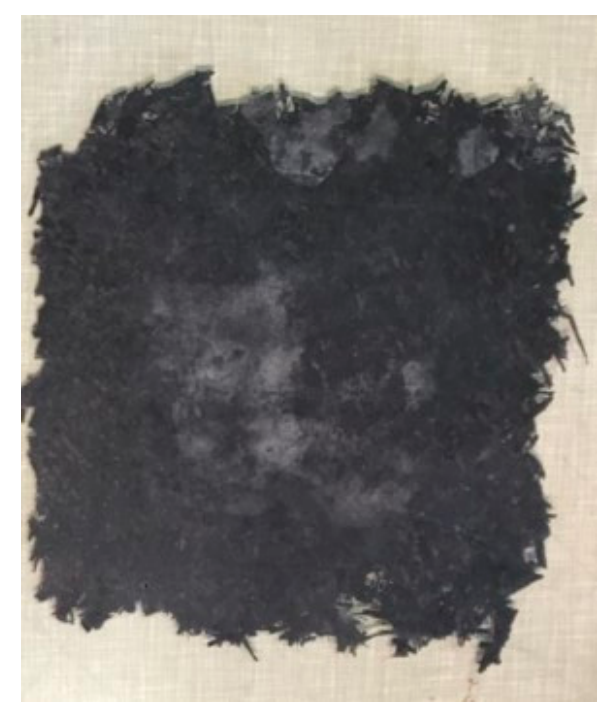

Figure 3. Recycled CFRP sample result from the autoclave curing cycle.

\section{Results and Discussion}

Upon closer observation, the samples were found to be quite stiff despite their small thickness. The next stage in the plan was to examine the mechanical properties of the processed CFRP waste. For this purpose, the cured sample was cut carefully using a sheet metal shear press to prepare tensile test samples in accordance with the geometry requirements of the ASTM code D3039M [43,44]. A tensile test machine (MTS, Instron $100 \mathrm{kN}$ ) was used to test the samples under $1 \mathrm{~mm} / \mathrm{min}$ speed. The whole pieces were tested until failure condition, and the data were collected and analyzed. Some useful Excel features and functions suggested by [45] were used in this study, and the estimated mechanical properties for the Young's Modulus and the ultimate strength of the samples that were tested are illustrated in Figures 4 and 5, respectively. It was found that the standard deviation of the modulus of elasticity in tension is $3361.5 \mathrm{MPa}$, which is attributed to the random orientation of the CFRP shreds that is reflected on the mechanical properties of the samples. Moreover, the tensile strength of the tested samples has a standard deviation of 82.6 MPa for the five samples due to the randomized orientation of the shredded CFRP pieces that cannot be controlled.

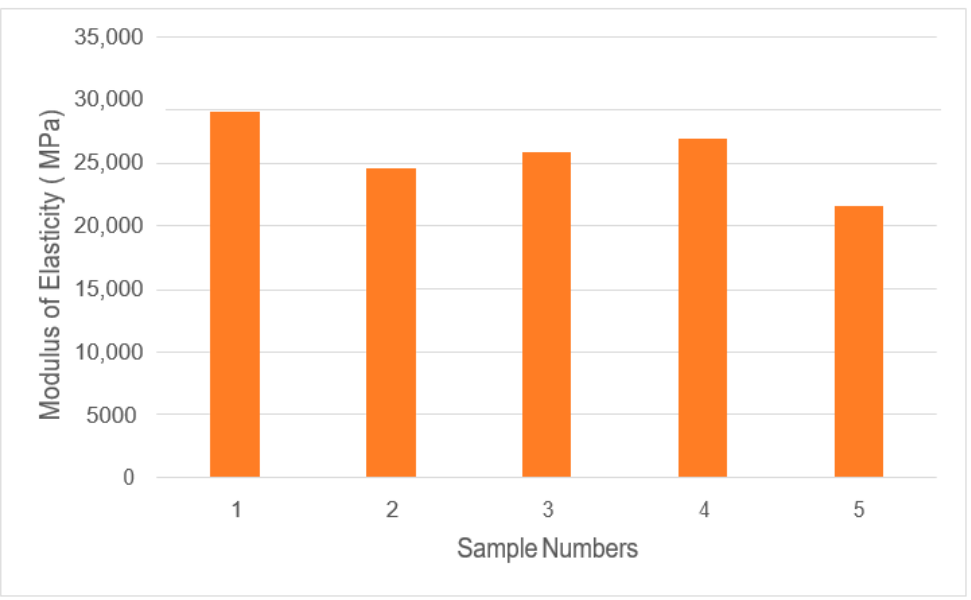

Figure 4. Young Modulus of the tested samples. 


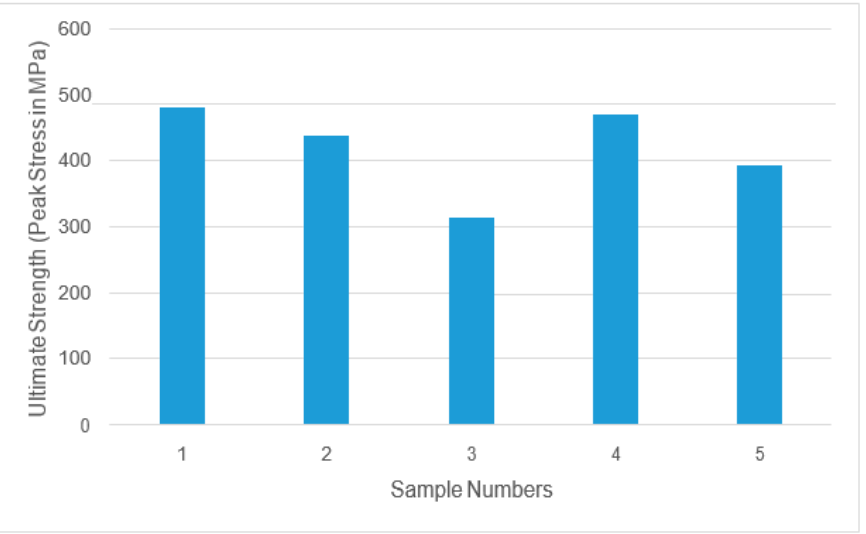

Figure 5. The ultimate strength of the tested samples.

It was observed that the maximum modulus of elasticity is less than $30 \mathrm{GPs}$, which is much lower than anticipated for the cured virgin CFRP. This result is due to the degradation of the epoxy used for the prepreg CFRP waste. Moreover, students were requested to calculate the mean value of the modulus of elasticity, which was found to be around $25.6 \mathrm{GPa}$ with a standard deviation of $2.5 \mathrm{GPa}$. On the other hand, the ultimate strength of the cured samples was less than $500 \mathrm{MPa}$ with a mean of $419.5 \mathrm{MPa}$ and a standard deviation of $60.1 \mathrm{MPa}$. It is worth mentioning that the team had come up with an innovative process to produce a nonstructural element that could be used for other domestic applications through processing the CFRP shreds with the colored back film, where an aesthetic tile was made through understanding the constraints of both CFRP and the nylon back film. The process was filed in the US patent office and has been recently published [46]. In the second cycle of the undergraduate aerospace research program, a second team of students continued the work on testing the waste CFRP. It was planned to design and build a compression mold for curing CFRP inside the university campus and test CFRP's compressive properties. A closed cylindrical mold was designed using the principles of the machine design and mechanics of material that the students studied through their undergraduate course, where the dimensions were drawn using CATIA, a software used for drawing and modeling [47]. The detailed engineering drawings were checked by the supervisor and considered to manufacture a compression mold from aluminum to process CFRP under a compression load, where a temperature regulation mechanism was designed to keep the curing temperature under control, as shown in Figure 6. The mold was equipped with figure heaters as well as connected with a thermostat circuit to control the temperature as per the need. With the help of the supervisor, a complete control circuit was built complying with electrical safety regulations using a dedicated earth leakage circuit-breaker for additional safety measures implemented in the design.
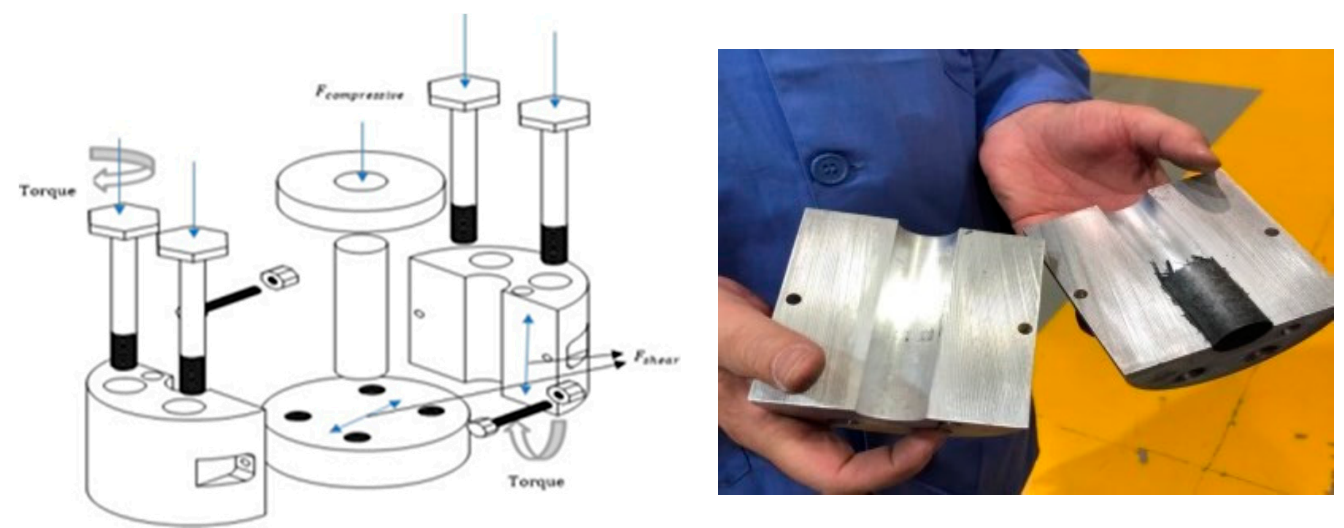

Figure 6. The designed and the manufactured mold. 
One of the educational aims of the student's participation was to distinguish between the mechanical properties of the material and how to measure them, literally the modulus of elasticity and the strength. The modulus of elasticity is defined as the ability of the material to resist the deformation within the elastic zone where the material is capable of recovering its shape and dimensions without suffering from permanent deformation; therefore, engineers use this property to design the products, whereas the strength of the material is the ability of the material to withstand the applied load without causing the plastic deformation that leads to the failure of the material.

Furthermore, it is worth noting that there is a significant difference between the modulus of elasticity and the samples' overall strength. This difference may have resulted from the variable quality or the condition of the carbon fiber recycling polymer pieces. Since the pieces were not adequately preserved after being used, the quality may have deteriorated. Moreover, the application of nonuniform pressure during the compression molding phase would have resulted in the difference in physical properties (i.e., strength and modulus of elasticity). Therefore, the prepreg recycled suffered from a reduction in the ultimate strength and modulus of elasticity in comparison with the virgin prepreg. The CFRP shreds were added to the mold and packed and then heated using controlled electrical heaters. The samples were compressed by a mechanical press to produce cylindrical samples and investigate the compressive mechanical properties of the recycled CFRP waste. In order to prepare the desired number of pieces (i.e., 10), the aforementioned procedure was used consistently. Figure 7 illustrates the mold and the samples produced.

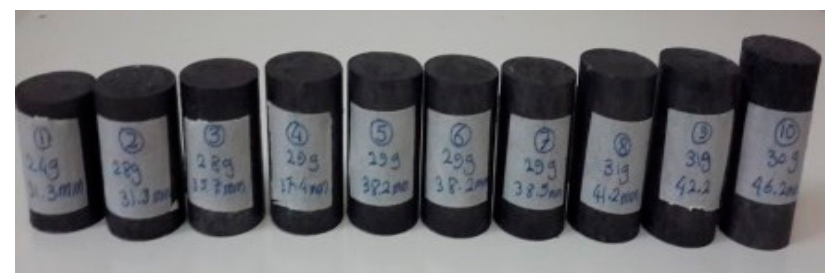

Figure 7. The produced samples using closed mold $(\mathrm{D}=25, \mathrm{H}=50 \mathrm{~mm})$.

The samples were then tested under $1 \mathrm{~mm} / \mathrm{min}$ speed and classified into three sets of samples due to the height discrepancy that results from the process, weighed, and tested under the compression test. The heights and weights of the produced samples are shown in Figure 8, which reflects the difficulty faced by the students to control the preliminary compression process to produce a compact piece that, at the end, led to the production of different heights and weights of the cylindrical samples. It was observed that there is a discrepancy in the made sample that is reflected on two parameters, the height, and the weight of the samples, which were therefore classified into three groups. The reason behind this is that the compaction process was done manually by weighing the shreds of the CFRP leftover pieces and trying to feed the mold step by step with the shreds and applying gradual pressure, and this was one of the observations of this research. In fact, the standard deviation of the height has been estimated to be $3.6 \mathrm{~mm}$, while the standard deviation of the weight was estimated to be $2.3 \mathrm{~g}$.
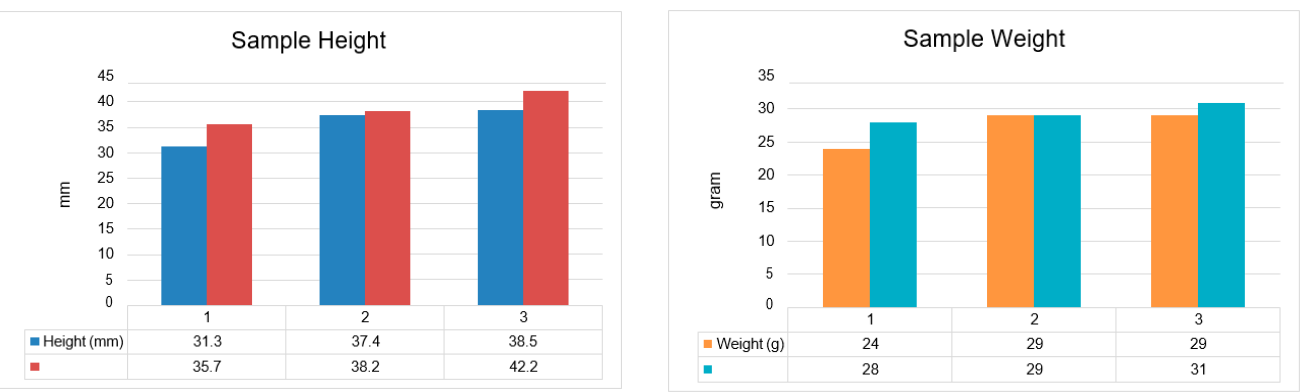

Figure 8. The height and weight of the produced CFRP samples. 
On the other hand, the samples were tested under compression conditions to estimate the mechanical properties of the tested samples, as illustrated in Figure 9. The estimated standard deviation of the modulus of electricity is $0.85 \mathrm{MPa}$, due to the discrepancy observed in height and the weight that is attributed to the compaction process. A similar impact was concluded for the 36.2 MPa compressive strength of the tested samples.
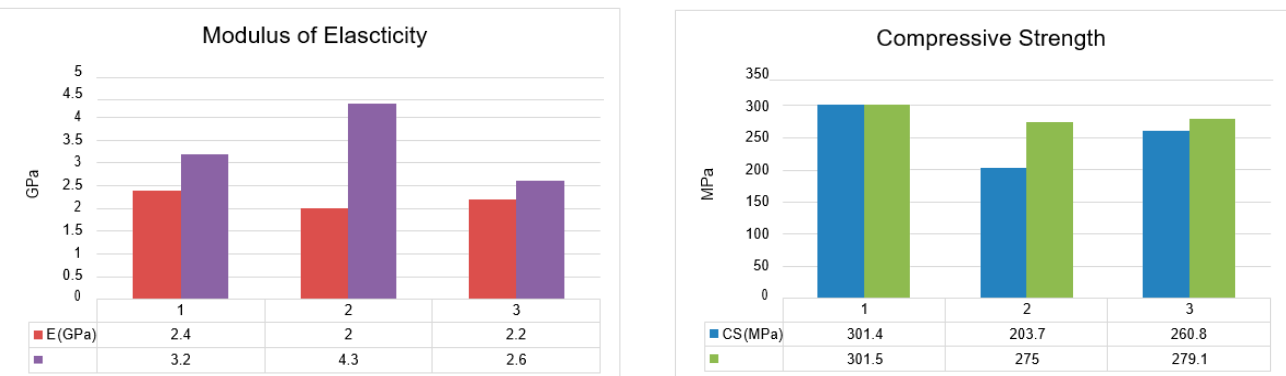

Figure 9. The modulus of elasticity and compressive strength for the produced sample.

The recycled prepreg's mechanical properties are compared with steel rather than virgin prepreg in order to look into alternatives for the large spectrum applications of steel in the aerospace, army, medical, and construction industries. The applications of virgin prepreg are already limited. Hence, this study can help decide on the replacement of steel in various applications despite the fact that the strength of recycled composite fibers deteriorates by $35 \%$ over its lifetime.

It has been concluded that the mechanical properties of the produced samples under a closed molding procedure have lower values under the compression load than expected due to the condition of the curing process that affects the results negatively.

Moreover, the reason for getting such results is partly due to the problem associated with the packing of the shreds using the closed molding as this problem was not faced using the open mold productions [48]. Practically, the impact is negatively significant, but at the same time, the time spent, the preparation procedure, and the energy consumed are much less than the autoclave process. This makes the latter process much more attractive and can be developed for better-anticipated properties. Moreover, compressive stresses were found using the relationship (i.e., $\sigma=\mathrm{F} / \mathrm{A}$ ); henceforth, the stress-strain curve shown in Figure 10 represents a sample that has the highest magnitude of compressive strength if the only elastic region is taken into account. The experience and knowledge that the students acquired through studying the 'engineering materials' and 'mechanics of materials' courses were useful for calculating the mechanical properties through the stress-strain curve, which is a result of the destructive compression testing.

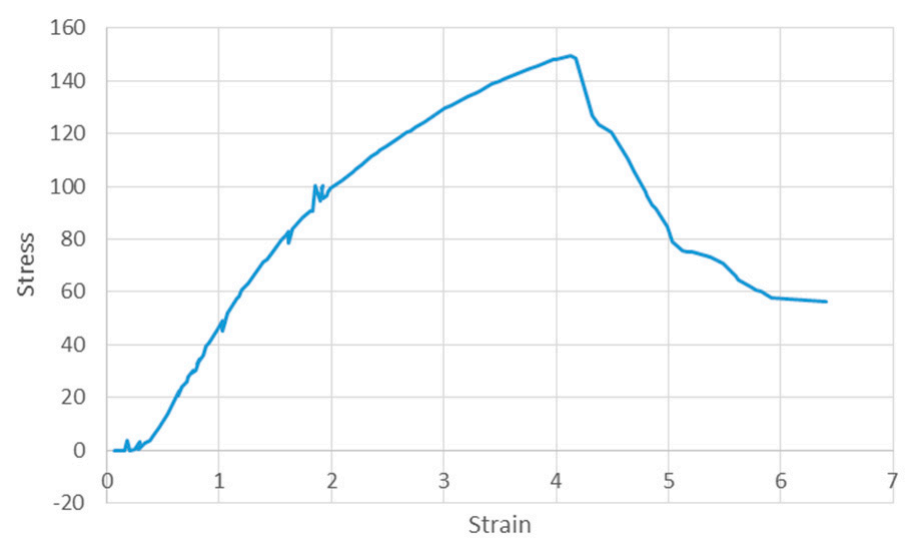

Figure 10. Stress-strain curve for the CFRP samples. 
The 'Summer Undergraduate Research Experience (SURE)' program initiated by the UAE University to promote the engagement and contribution of undergraduate students in research activities helped train students, expose them to research work, and encourage them to engage in several research opportunities while collaborating with other students from different disciplines at the undergraduate and graduate levels under the supervision of experienced faculty members. This initiative provided a great opportunity and support to undergraduate students to be involved in research activities and prepare them to be good researchers in the future. The novelty of this study is that it is the first of its kind in a country that focuses on research conducted by undergraduate students as part of their education. Undergraduate students typically earn their bachelor's degree with very limited or even no experience on how to conduct research. Moreover, local waste of CFRP has been increasing recently due to booming growth in using carbon fiber; therefore, part of the commitment toward the society from the university was to increase the awareness through the students by engaging with research projects trying find with solutions to reduce the negative impact. A complete program was designed for the students to be trained on handling the waste in order to proceed with the planned activities, since gaining hands-on skills is an essential matter for the students to acquire knowledge in order to cope with the diverse demands of working life $[49,50]$.

\section{Conclusions}

This study was performed under the initiative of UAE University to promote research activities among undergrad students in order to prepare the new generation of students for the market while studying at the university. This is important since potential employers require fresh graduates to have research experienced and developed soft skills [51]. This requirement becomes an obligation to the universities nowadays to tackle the changing requirements of the job market and make the university environment adapt to emerging needs and trends.

The scope of study involved making CFRP from waste composite materials. The scope was divided among three student groups. The first step involved shredding, autoclave, and dissolving in solvents; the second step involved heat cure and compression molding. Subsequently, material testing was carried out. The results confirm that carbon fiber waste has the potential to be used for recycled parts. The values of mechanical properties (i.e., modulus of elasticity and compressive strength) are indeed competitive and, thus, optimum as an alternate material for structural applications. The inconsistencies in the experimental values are due to discrepancies in the procedure as a result of the lack of specialized equipment for handling CFRP waste material.

This study also suggests several future research possibilities. As a possible future research work, the experimental results can be further enhanced by implementing the following recommendations:

(i) Design and fabrication of apparatus for prompt handling and storage of CFRP shreds under constant pressure.

(ii) Optimum storage compartments for CFRP powder to prevent contamination.

(iii) Design multicave molds to multiply sample production.

(iv) Produce variable quality sample by providing different temperature and pressure conditions. The shreds can also be powdered to check to obtain better quality samples too.

(v) Understand and comply with safety regulations related to process prepreg waste.

(vi) Use engineering standardizations related to testing of the material.

Other faculty members attracted undergraduate students to engage with a new experience in the undergraduate research opportunities sponsored by different programs in the university. The team had participated in various research competitions and local exhibitions to present their achievements. They were even asked to apply for an incubator fund to develop their projects to establish a startup business. Accordingly, we appreciate these undergraduate research opportunities launched in the university, offering the stu- 
dents the opportunity to develop their research capabilities and skills and gain hands-on experience. With such research opportunities, students become more attractive in the job market regarding their expertise and practical background.

The research experience indicated that incorporating project-based practical activities has a positive impact on student learning, motivation, and performance both in the short and long term [52]. In addition, incorporating a research project expands students' knowledge and boosts their real-life skills, which encourages the formation and development of real-life competencies. Therefore, this research experience is expected to encourage other students to seek such exceptional opportunities that would give them valuable experience and help them find competitive job opportunities locally and internationally.

Author Contributions: Technical supervision, coordination and conceptualization, W.A.; Methodology, analysis, writing, and editing, E.Z.; Writing and editing, A.A.H. All authors have read and agreed to the published version of the manuscript.

Funding: This research was funded by Undergraduate Aerospace Research Opportunities programm under UAE Unievrsity.

Conflicts of Interest: The authors declare no conflict of interest.

\section{References}

1. Pickering, S.J. Recycling technologies for thermoset composite materials-Current status. Compos. Part A 2006, $37,1206-1215$. [CrossRef]

2. Carberry, W. Airplane recycling efforts benefit Boeing operators. Boeing AERO Mag. QRT 2008, 4, 6-13.

3. Buntrock, R.E. Creating effective undergraduate research programs in science: The transformation from student to scientist. Choice 2008, 46, 532.

4. Ahmed, W.; Alnajjar, F.; Zaneldin, E.; Al-Marzouqi, A.H.; Munkhjargal Gochoo, M.; Khalid, S. Implementing FDM 3D printing strategies using natural fibers to produce biomass composite. Materials 2020, 13, 18. [CrossRef]

5. Taraban, R.; Blanton, R.L. Creating Effective Undergraduate Research Programs in Science: The Transformation from Student to Scientist; Teachers College Press: New York, NY, USA, 2008.

6. Lopatto, D.; Tobias, S. Council on Undergraduate Research (U.S.), Research Corporation for Science Advancement. In Science in Solution: The Impact of Undergraduate Research on Student Learning, 1st ed.; Council on Undergraduate Research: Washington, DC, USA, 2010.

7. Bridger, A.R.; Ford, R.M. Undergraduate student research engagement through the open laboratory model. New Dir. High. Educ. 2019, 185, 57-69. [CrossRef]

8. Chris, C.; McKay, T.; Mazzeo, A.; Morris, J.; Prigodich, C.; De Groot, R. Cross-Discipline perceptions of the undergraduate research experience. J. High. Educ. 2011, 82, 92-113.

9. Elaine, S.; Hunter, A.B.; Laursen, S.L.; DeAntoni, T. Establishing the benefits of research experiences for undergraduates in the sciences: First findings from a three-year study. Sci. Educ. 2004, 88, 493-534.

10. Marcus, F.; Webber, K.; Kleiber, P.B. How well do undergraduate research programs promote engagement and success of students? CBE Life Sci. Educ. 2011, 10, 156-163.

11. Webber, K.L.; Laird, T.F.N.; BrckaLorenz, A.M. Student and faculty member engagement in undergraduate research. Res. High Educ. 2012, 54, 227-249. [CrossRef]

12. Griffioen, M.E. The influence of undergraduate students' research attitudes on their intentions for research usage in their future professional practice. Innov. Educ. Teach. Int. 2018, 56, 162-172. [CrossRef]

13. Morales, X.D.; Grineski, S.E.; Collins, T.W. Faculty motivation to mentor students through undergraduate research programs: A study of enabling and constraining factors. Res. High. Educ. 2016, 58, 520-544. [CrossRef] [PubMed]

14. Wolf, L.W. Undergraduate research as engaged student learning. New Dir. Teach. Learn. 2018, 2018, 75-85. [CrossRef]

15. Stefanucci, J.K. Publish with undergraduates or perish? Strategies for preserving faculty time in undergraduate research supervision at large universities and liberal arts colleges. Front. Psychol. 2019, 10, 828. [CrossRef] [PubMed]

16. Cooper, K.M.; Gin, L.E.; Akeeh, B.; Clark, C.E.; Hunter, J.S.; Roderick, T.B.; Brownell, S.E. Factors that predict life sciences student persistence in undergraduate research experiences. PLoS ONE 2019, 14, 8. [CrossRef] [PubMed]

17. Adams, S.K. Empowering and motivating undergraduate students through the process of developing publishable research. Front. Psychol. 2019, 10, 1007. [CrossRef]

18. Long, A.; Bischoff, W.R.; Aduddell, K. Research prescription for undergraduate students: Research mentoring in a small liberal arts university. J. Prof. Nurs. 2018, 35, 170-173. [CrossRef]

19. Mann, G.; Bishop, T.U.; Kaiser, K.; Cafer, A. College2Youth: Design of multidisciplinary interdisciplinary undergraduate research experience. J. Nutr. Educ. Behav. 2020, 52, 447-450. [CrossRef]

20. Peifer, J.S. Context and reasons for bolstering diversity in undergraduate research. Front. Psychol. 2019, 10, 336. [CrossRef] 
21. Liu, Y.; Yang, C.; Ma, J.; Xu, W.; Hua, Z. A social recommendation system for academic collaboration in undergraduate research. Expert Syst. 2018, 36, e12365. [CrossRef]

22. Boyles, C.T.; Moynihan, A.R.; Mulroy, J.D.; Fitch, B.; Watts, P.J.; Evans, J.L. Undergraduate student experiences with composite materials. Int. J. Mech. Eng. Educ. 2011, 39, 297-305. [CrossRef]

23. Saliba, M.A.; Cassar, D.J.; Axiak, M. Undergraduate mechatronics research case study: Contributing towards a dexterous robot hand. Int. J. Mech. Eng. Educ. 2012, 40, 234-250. [CrossRef]

24. Stappenbelt, B. Undergraduate mechanical engineering research project work in an action learning environment. Int. J. Mech. Eng. Educ. 2009, 37, 326-340. [CrossRef]

25. Bishay, P.L. Introducing undergraduate research in numerical analysis of engineering systems course. Int. J. Mech. Eng. Educ. 2018, 46, 345-361. [CrossRef]

26. Schaefer, D.; Panchal, J.H. Incorporating research into undergraduate design courses: A patent-centered approach. Int. J. Mech. Eng. Educ. 2009, 37, 98-110. [CrossRef]

27. Stöckert, A.; Bogner, F.X. Cognitive learning about waste management: How relevance and interest influence long-term knowledge. Educ. Sci. 2020, 10, 102. [CrossRef]

28. Sanganyado, E.; Nkomo, S. Incorporating sustainability into engineering and chemical education using E-learning. Educ. Sci. 2018, 8, 39. [CrossRef]

29. Witik, R.A.; Teuscher, R.; Michaud, V.; Ludwig, C.; Månson, J.A.E. Carbon fibre reinforced composite waste: An environmental assessment of recycling, energy recovery and landfilling. Compos. Part A 2013, 49, 89-99. [CrossRef]

30. Meyer, L.O.; Schulte, K.; Grove-Nielsen, E. Optimisation of a pyrolysis process for recycling of CFRP's. In ICCM-16; Japan Society for Composite Materials: Kyoto, Japan, 2007.

31. Pickering, S.J.; Kelly, R.M.; Kennerley, J.R.; Rudd, C.D.; Fenwick, N.J. A fluidised-bed process for the recovery of glass fibres from scrap thermoset composites. Compos. Sci. Technol. 2000, 60, 509-523. [CrossRef]

32. Pimenta, S.; Pinho, S. Recycling carbon fibre reinforced polymers for structural applications: Technology review and market outlook. Waste Manag. 2011, 31, 378-392. [CrossRef]

33. Marsh, G. Carbon recycling: A soluble problem. Reinf. Plast. 2009, 53, 22-27. [CrossRef]

34. Marsh, G. Reclaiming value from post-use carbon composite. Reinf. Plast. 2008, 52, 36-39. [CrossRef]

35. Nadeem, M.; Chandra, A.; Livirya, A.; Beryozkina, S. AR-LabOr: Design and assessment of an augmented reality application for lab orientation. Educ. Sci. 2020, 10, 316. [CrossRef]

36. Liu, Y.; Farnsworth, M.; Tiwari, A. A review of optimisation techniques used in the composite recycling area: State-of-the-art and steps towards a research agenda. J. Clean. Prod. 2007, 140, 1775-1781. [CrossRef]

37. Pimenta, S.; Pinho, S.T. The effect of recycling on the mechanical response of carbon fibers and their composites. Compos. Struct. 2012, 94, 3669-3684. [CrossRef]

38. Dong, P.A.; Azzaro-Pantel, C.; Cadene, A. Economic and environmental assessment of recovery and disposal pathways for CFRP waste management. Resour. Conserv. Recycl. 2018, 133, 63-75. [CrossRef]

39. Turhan, D.; Celep, Z.; Zain-Edden, I.K. Transient wave propagation in layered media conducting heat. J. Sound Vib. 1991, 144, 247-261. [CrossRef]

40. Ma, Y.; Kim, D.; Williams, T.; Nutt, S. Recycling of carbon fiber composites using chemical treatment: Reaction characterization and optimization. In Proceedings of the The Society for the Advancement of Material and Process Engineering(SAMPE), Seattle, WA, USA, 14-16 November 2017.

41. Yu, K.; Shi, Q.; Dunn, M.L.; Wang, T.; Qi, H.J. Carbon fiber reinforced thermoset composite with near $100 \%$ recyclability. Adv. Funct. Mater. 2016, 26, 6098-6106. [CrossRef]

42. Law No.21 of 2005 Waste Management in the Emirate of Abu Dhabi; Emirates of Abu Dhabi: Abu Dhabi, United Arab Emirates, 2005; Chapter I, II \& III, Article 1, 2 \& 3.

43. ASTM D3039/D3039M-17. ASTM International—Standards Worldwide. Available online: www.astm.org/Standards/D3039 (accessed on 15 June 2021).

44. Bindurani, P.; Ganesan, N.; Indira, P.V. Tensile properties of FRP and Ferrocement-A comparative study. In Advances in Civil Engineerin; Lecture Notes in Civil Engineering; Singh, R.M., Sudheer, K.P., Kurian, B., Eds.; Springer: Berlin/Heidelberg, Germany, 2021; Volume 83, pp. 391-405. [CrossRef]

45. Zaneldin, E.; Ashur, S. Using spreadsheets as a tool in teaching construction management concepts and applications. In Proceedings of the 2008 American Society of Engineering Education (ASEE) Annual Conference, Pittsburgh, PA, USA, $22-25$ June 2008.

46. Ahmed, W.; Alnaqbi, A.; Almazrouei, A.; Almarzooqi, L.; Al Jamal, D.; Genena, F. Method of Recycling Carbon Fiber Prepreg Waste. U.S. Patent 10,328,610, 25 June 2019.

47. Adam, S.A.A.; Zhou, J.; Zhang, Y. Modeling and simulation of 5DOF robot manipulator and trajectory using MATLAB and CATIA. In Proceedings of the 3rd International Conference on Control, Automation and Robotics (ICCAR), Nagoya, Japan, 24-26 April 2017; Available online: https:/ / ieeexplore.ieee.org/abstract/document/7942657 (accessed on 15 June 2021).

48. Louisy, E.; Samyn, F.; Bourbigot, S.; Fontaine, G.; Bonnet, F. Preparation of glass fabric/poly(l-lactide) composites by thermoplastic resin transfer molding. Polymers 2019, 11, 339. [CrossRef] [PubMed]

49. Pócsová, J.; Bednárová, D.; Bogdanovská, G.; Mojžišová, A. Implementation of agile methodologies in an engineering course. Educ. Sci. 2020, 10, 333. [CrossRef] 
50. Ngereja, B.; Hussein, B.; Andersen, B. Does Project-Based Learning (PBL) promote student learning? A performance evaluation. Educ. Sci. 2020, 10, 330. [CrossRef]

51. Habib, M.K.; Nagata, F.; Watanabe, K. Mechatronics: Experiential learning and the stimulation of thinking skills. Educ. Sci. 2021, 11, 46. [CrossRef]

52. Väisänen, S.; Hirsto, L. How can flipped classroom approach support the development of university students' working life skills?-University teachers' viewpoint. Educ. Sci. 2020, 10, 366. [CrossRef] 